\section{Observations of the Leonid Meteors, Ig04}

ObServations by the writer this year go to show that the intensity was much below that of last. Briefly, the nights of November 12 and 13 were heavily overcast, but the night of November 14 and early morning of November 15 were fortunately clear. The display lasted about an hour, say from 12.30 until 1.30 a.m., maximum i o'clock a.m. (local times), hourly rate, low, 20 to 25 . Bright meteors, however, continued to appear at intervals up to 3 a.m., when clouds coming on stopped further observation. A couple of hours' watch before and after midnight of November is gave only two Leonids, while another two hours' watch on the night of November 16 showed the radiant, which was sharply defined the previous nights, at $150^{\circ}+23^{\circ}$, near Zeta, to be quite quiescent. Other radiants active were :-

\begin{tabular}{llllll}
\multicolumn{7}{c}{ R.A. Dec. } \\
0 & 0 \\
(1) Leonids (No. 2) & $\ldots$ & $165+25$ & $\ldots$ & Strong, bright. \\
(2) Ursids $\ldots$ & $\ldots$. & $\ldots$ & $155+47$ & $\ldots$ & $\ldots$, \\
(3) Præsepids & $\ldots$ & $\ldots$ & $125+20$ & $\ldots$ & Slow, small, wiry. \\
(4) Cancrids & $\ldots$ & $\ldots$ & $130+5$ & $\ldots$ & Short, bright. \\
(5) Geminids & $\ldots$ & $\ldots$ & $108+28$ & $\ldots$ & (One) short, bright.
\end{tabular}

It would be interesting to hear of observations made during the hour or so before daybreak on the morning of November 15 , as it is just possible the increased intensity noticed in previous years may not be real, but due rather to the fact of the radiant being near the meridian, and the smaller meteors coming down more direct at that time are the better able to penetrate to the lower layers of the atmosphere.

Holywood, co. Down, November 18. W. H. MillignN.

\section{The Discovery of Argon.}

IN your translation of Prof. Mendeléeff's interesting paper on the chemical elements (November 17, p. 94) I see that he attributes the discovery of argon and its congeners to Ramsay. Am I not right in believing that it was Lord Rayleigh who discovered argon, and that it was he who gave that impulse to chemistry which Sir William Ramsay has carried forward to such remarkable results?

November 20.

G. H. DARWIN.

\section{Blue-stained Flints.}

SOME years ago there were many blue-stained fints on a road near Cambridge. Lime from gas-works was about to be mixed with the flints used as road-metal, and the two different materials had lain for some time in heaps by the roadside. The blue colour, in some instances very intense, was developed wherever a heap of flints and one of lime touched each other; from which I surmised that the calcium sulphide of the gas-lime had reacted with an aluminium compound present in the flints, producing a substance akin to ultramarine.

Cambridge, November 19 .

\section{Inheritance of Acquired Characteristics.}

IT may be worth noting that since my letter to you of some months back, in which I gave an instance of foxterrier pups being born with short tails, I have heard of two similar cases. In one of these cases the dog was owned by one of the managers of the Rhodes' Fruit Farms, near Cape Town. The other case occurred in the Transvaal at $\mathrm{Sabi}$, one out of a litter of four being born with a short tail.

Forest Office, Cape Town, October 18. D. E. Hutchins.

\section{DR. KOENIG'S METHOD OF COLOUR PHOTOGRAPHY.}

I $\mathrm{N}$ the methods of three-colour photography hitherto practised the colours are used as inks, stains, or pigments already prepared, and their distribution is effected indirectly by the action of light. In the imbibition process three thin gelatin reliefs are prepared (using potassium bichromate to sensitise the gelatin), and after each relief is stained with its appropriate colour the three films are superposed. The method recently described by Dr. Koenig is of the multiple film kind, but the colours are produced by direct exposure to light.

Many organic colouring matters yield by reduction colourless bodies that are more or less easily re-oxidised with the production of the original colours. The oxidation of these leuco colouring matters is generally if not always quickened by light. If, therefore, the leuco-compound produced from a dye of a suitable red colour is caused to impregnate a film, and this is exposed beneath the negative made to give the red image in three-colour work, the red image may be produced by direct exposure to light. A similar procedure will of course give the yellow and blue images, and so the complete colour print may be obtained. Such are the general principles upon which Dr. Koenig's process depends, but to elaborate the details of a successful process on these lines it was necessary to overcome many practical difficulties.

It was necessary, in the first case, to select only those dyes (of suitable colours, of course) that yield leucoderivatives of sufficient stability to stand the necessary manipulations. Then it was found that the leucobases selected as otherwise suitable gave but a feeble image even after long exposure; but it was observed that when collodion was used as the medium the sensitiveness was greatly enhanced, and the vigour of the image very much improved. This improvement was traced to the action of the nitrocellulose, and other nitric acid esters were found to have a still greater effect. Nitromannite especially is useful for sensitising purposes. Dr. Koenig emphasises the fact that the leuco-bases in an inert film are useless, as the action of aërial oxygen, when it has reached its maximum, gives only a flat and feeble image.

The fixing of the image was the next difficulty, for obviously it is necessary to remove the excess of the leuco-body without interfering with its coloured oxidation product. It is well known that many dyes show a great tendency to remain attached to a fabric or film in spite of the application of solvents, but the leuco-bases employed also have a similar tendency. Dilute mineral acids, though they dissolve the greater number of the leuco-bases, would not remove them fro', collodion films. A Io per cent. solution of monochloracictic acid was found to be the best fixing agent.

The various solutions required are supplied ready for use, and the following summary of the instructions issued with them will give a general idea of the manipulation required. A piece of baryta coated paper rather larger than the negative has its edges turned up, and is coated with a $1 \frac{1}{2}$ per cent. collodion to which has been added the leuco-derivative of the biue dye and a solution containing the necessary additions. When dry it is exposed under the appropriate negative (for, say, twenty to forty seconds in bright sunshine), soaked in the fixing bath for a few minutes, washed for a few minutes, dipped into a gelatin solution that contains a little chrome alum, and hung up to dry. The print is then turned so that its lower edge shall be uppermost, again dipped into the gelatin solution, and again allowed to dry. The gelatin coating is applied to isolate the collodion film so that it may not be interfered with by the application of the second collodion. The print is then coated with collodion to which the materials for the blue image have been added, exposed under the proper negative, fixed, and coated twice with gelatin as before. A similar procedure follows for the yellow image, and after the final gelatin coating it is well to varnish the print. It is claimed for the dyes employed that the blue, which is the one most liable to change, is more permanent than Prussian blue. 